\title{
Do high technology agglomerations encourage urban sprawl?
}

\author{
Daniel Felsenstein \\ Department of Geography, Hebrew University of Jerusalem, Mount Scopus, Jerusalem, Israel \\ (e-mail: msdfels@mscc.huji.ac.il)
}

Received: March 2001/Accepted: April 2002

\begin{abstract}
This paper looks at the impact of high technology employment concentrations on urban sprawl. A methodology for translating spatial employment patterns, into place of residence patterns, is presented. On this basis, the consumption of land at the urban fringe due to both residential and nonresidential uses, is estimated. The method is tested empirically using data relating to the two main outer suburban agglomerations of high technology activity in the Chicago metropolitan area. Two counter-factual situations are simulated. The first relates to a spatial counter-factual whereby the high tech concentrations develop in the city of Chicago or within the inner suburbs. The second presents an industry counter-factual that estimates the land consumption impacts arising from the development of an alternative industrial concentration in the same location. The results of the actual and hypothetical cases are compared. They point to a considerable saving in acreage in all alternative scenarios. Some policy implications are highlighted.
\end{abstract}

JEL classification: R12, R14, R33

\section{Introduction}

While much is known about the locational behavior of high technology industries and their tendency to agglomerate, surprisingly little work has been done on the relationship between these industries and the process of urban sprawl. Separately, both the land consumption effects of employment suburbanization (Ding and Bingham 2000) and the role of high technology employment as a key to local economic development (Shearmur and Doloreux 2000), have attracted much attention recently. However little attempt has been made to forge a link between the two. This is surprising in view of the intuitive per-

Thanks to three anonymous referees for constructive criticism on an earlier draft, to Joe Persky for advice and to Tim Angell Lake County Department of Planning and Development and Bill Syverson, County Community Development, DuPage County who provided access to firm-level employment data. The work was undertaken when the author was Senior Research Fellow at the Great Cities Institute, University of Illinois at Chicago. 
ception of high technology firms as occupying land-extensive facilities in parklike settings at the city perimeter and employing high wage labor with a preference for outer-suburban, low-density residence. While this caricature may be exaggerated it does suggest that high technology-induced urban sprawl is likely to be even more land-intensive than other forms of suburbanizing economic activities.

The spatial behavior of high technology industries creates distinctive locational patterns at both inter and intra-metropolitan scales. At the intermetropolitan scale, the tendency to seek out new locations and create new agglomerations in new places, has been well noted (Markusen et al. 1986; Feldman 1994; Acs and Ndikumwami 1998; DeVol 1999). For our purposes however, the intra-metropolitan behavior of high tech industries is of more significance. New suburban employment clusters within the orbit of the metropolitan area have been recognized as major components of the polycentric city (McDonald 1987; Giuliano and Small 1991; Anderson and Bogart 2001). These new agglomerations invariably cause pressure on land and housing markets via the redesignation of land uses, the incorporation of unincorporated land, annexations and the like. When these employment centers specialize in high technology there is reason to believe that demand for land consumption will intensify. The housing preferences and amenity-intensive lifestyle of high tech workers are reflected in demand for low density and single-family homes, proximity to retail and entertainment centers and the like (Herzog and Schlottman 1991; Malecki and Bradbury 1992). Through the consumption patterns of their labor force, high technology employment agglomerations are therefore likely to impact on the process of suburbanization, irrespective of their actual location within the metropolitan area.

Surprisingly, the resurfacing of the debate on the costs and benefits of urban sprawl (Burchell 1997; Brueckner 2000; Landis 2001), has not heralded an assessment of the differential impacts of economic activities on metropolitan expansion. This study attempts to make this link in the context of high technology industries. It offers empirical measurement of how workplace concentrations of high technology activity translate into metropolitan sprawl, based on the outward extension of residential communities. We examine the case of outer suburban high technology agglomeration in the Chicago metropolitan area and look first at the impact this employment suburbanization has on its immediate areas and on other parts of the metropolis. Then we simulate two counter factual situations. The first relates to a spatial counterfactual. We ask what would happen if these concentrations were hypothetically transplanted to other parts of the metropolitan area. Would there be the same pressure on the outer suburbs or, would more central-city or inner suburban residents be employed thereby lessening the pressure for outer suburban residential development? Second, we simulate an industry counter-factual, observing whether the development of an alternative industrial agglomeration in the same location would give rise to a different magnitude of land consumption in the outer suburbs.

The paper proceeds in the following manner. The existing evidence on the relationship between high technology location and urban sprawl is reviewed and the particular case of high tech development in Chicago is highlighted. Then the method and data employed in this analysis is presented. This involves a simple micro-simulation that translates place-of-work patterns into place-of-residence patterns. Preliminary estimates of the amount of outer sub- 
urban land consumed in the present case are presented and are compared with alternative development scenarios in order to assess their relative sprawlinducing impacts. The paper concludes with some policy implications and calls for a more explicit distributional focus in the 'costs of sprawl' debate.

\section{High technology location and urban sprawl}

We can identify three traditions that relate to the potential connection between high technology location and urban sprawl. Perhaps the most developed is the urban economics approach to intra-urban location. Much of this work is concerned with unraveling the links between urban form and economic performance. If the polycentric structure of the modern metropolis is economically efficient, this should be reflected in the performance of those economic agents that locate in the many nuclei of the dispersed city. Efficiencies are derived from labor pooling between proximate firms, production linkages and benefits derived from local information flows. Together, these comprise the classic ingredients of localization economies (Bogart 1998). A further factor often included relates to the co-location of employment and housing which can lower transportation costs and increase labor productivity (Cervero 1989). Empirically, these factors are tested by estimating the impact of exogenous determinants on the performance of high technology firms. The assumption is that intra-urban differences in performance reflect different locational advantages. Invariably, these determinants coalesce around three main groups: production advantages such as proximity to local universities (Feldman 1994; Varga 1998), skilled labor pools (Herzog and Schlottman 1991) or transportation infrastructure (Markusen et al. 1986); consumption advantages as expressed in variations in urban amenities and quality of life factors (Malecki and Bradbury 1992; Gottlieb 1994; Glaeser et al. 2001); and supply side constrains as reflected in planning and zoning controls (Ding et al. 1999).

Results from a variety of studies provide support for the contention that urban form is related to economic performance. However much of this is at a very high level of aggregation, pointing to the link between urban size or density and industry productivity (Beeson and Montgomery 1993; Glaeser et al. 1992; Varga 1998). Recent evidence produced by Cervero (2001) relating to productivity of firms in sub-districts in the San Francisco Bay area reinforces these findings. Other work has looked at the within-metropolitan variation of real estate rents for $\mathrm{R} \& \mathrm{D}$ property, arguing that they reflect locational preferences of firms and their employees (Sivitanidou and Sivitanides 1995). This has shown the role of production and consumption factors as significant determinants of intra-urban high tech location.

Most of these studies have highlighted the localization economies embodied especially in technological spillovers, to be realized from intra-metropolitan clustering in high tech. Evidence presented by Suarez-Villa and Walrod (1997) presents a different perspective. On the basis of work conducted in Los Angeles, they find that that polycentric urban form does not necessarily confer any advantages in terms of research-intensity or performance of high tech firms. They suggest that the highly diffuse structure of the Los Angeles metropolitan region serves to make the externalities previously available only in agglomerations, more readily accessible to all. 
A second tradition relating to the issue of high technology location and sprawl is the planning tradition. This focuses on the issue of the reciprocity between employment and housing allocation within the city. Ostensibly, the 'jobs-housing balance' (Cervero 1989, 1996) is a normative planning tool aimed at relieving traffic congestion and improving environmental quality in the face of market failure. The rational and simultaneous allocation of land to these two uses has been the sources of much urban modeling interest since the seminal works of Garin (1966) and Lowry (1964). However, an important issue that has been given less attention is the direction of causality in the jobsresidence relationship. This is a complex subject with inherent multi-causality: jobs follow people and people follow jobs. The evidence on this is far from unequivocal (Steinnes 1982; Thurston and Yezer 1994). Recent findings do seem to point to the former: jobs follow people and the demand of the latter for suburban lifestyles determines the extent of suburbanization (Glaeser and Kahn 2001).

In the context of high technology agglomeration and sprawl, this finding cannot be understated as a disparate body of empirical evidence suggests the opposite sequence, i.e. people follow jobs. High technology flagship employment centers such as science parks and government laboratories have been credited with producing the seeds of metropolitan expansion. Stories from different high technology locations such as Lawrence Livermore Labs in California, the British defense establishment facilities astride the M-4 motorway west of London, Bell Labs in New Jersey, French government research centers in Sophia Antipolis and Federal facilities in the Research Triangle in North Carolina, all point to high tech 'anchor' projects spawning residential development in their wake (Markusen et al. 1986; Catells and Hall 1994; Luger and Goldstein 1991). In view of the primordial role of high skilled labor and their consumption preferences, the direction of causality suggested in these studies, would seem questionable.

Finally, the third tradition that relates to the high tech - urban sprawl connection is the economic development tradition. Economic development practitioners and policy makers have an arsenal of strategies at their disposal, ostensibly for promoting local growth. These include industrial recruitment, sectoral targeting, import substitution, promoting entrepreneurship, cluster development and the like (Eisinger 1988). High technology development overlaps many of these and has become a popular strategy bound up with the development of flagship projects such as science parks, technology incubators and the like (Reese 1992). However it can lead to ambiguous consequences. In the competitive environment of inter-jurisdiction boosterism, economic development practitioners and local politicians have frequently opted for the high profile, high tech projects likely to embellish the local tax base. This is often to the exclusion of other economic development options perhaps more suited to local needs, skills and infrastructure.

In places of high demand, revenue-generating projects such as technology parks and office and business complexes are encouraged. Fiscally draining projects such as residential development and the provision of public services to accompany the expansion of employment centers are avoided. The result is a spatial division between bedroom communities and employment communities with severe fiscal consequences for the former and deficiencies in public service provision in the latter. This is particularly noticeable in areas characterized by many contiguous, outer metropolitan jurisdictions that have 
developed on the back of the high tech boom. The Washington DC - North Virginia region for example, is characterized by fast-growth communities powered by the development of high tech service firms (Stough et al. 1998). In this area, spurts of high tech office and retail development have concentrated in edge cities while residential development has by-passed these locations in preference for communities more suited to the lifestyle that edge city workers demand (Cervero 1996).

A further consequence of the local economic development interest in high tech development relates to the effectiveness of the strategy of attracting high tech to suburban communities. Empirical evidence suggests that high tech industries seek out wealthier communities even in the absence of local economic development activity (Schneider and Kim 1996). The implications of this finding are twofold. First, it suggests that local economic development spending in outer metropolitan communities may simply be 'deadweight' spending. Second, and perhaps more significantly, given the suburban locational preferences of high tech activity, it implies the existence of a cumulative growth process. High tech industries seek out more affluent communities further increasing both private wealth through their consumption patterns and those of their labor force and public wealth through embellishing the tax base.

\section{The development of the Chicago high technology agglomerations}

The increasing returns that characterize the growth of high technology locations, combined with historical 'lock in', can explain why some places develop as high technology concentrations while other eminently suitable locations, seem to 'miss the boat' (Krugman 1991; Audretsch 1998). Ostensibly, this would seem to describe the Chicago situation up until the early 1990's. The two suburban agglomerations of high technology employment examined in this paper, the I-88 cluster in DuPage County and the I-94 concentration in the southern part of Lake County (Map 1), have both experienced major growth spurts over the last decade. Prior to that, Chicago was never recognized as a major center for high technology despite the fact that on all indices relating to innovation potential, the Chicago SMSA is highly ranked. Recent rankings of the top US high tech centers, consistently place Chicago in the top ten locations across a wide range of indicators (Kotkin and DeVol 2001; Markusen et al. 2001). As a 'tech pole' (a composite measure of spatial concentration and share of national high tech output), the Chicago MSA ranked eighth place nationally in 1998. In this same ranking for 1978, Chicago did not even appear in the top 25 metropolitan areas (DeVol 1999).

Considering the existence of infrastructure for innovation, it is surprising that Chicago did not develop any major high technology concentration akin to Silicon Valley or the clusters developed in Boston, Raleigh-Durham, Salt Lake City or Northern Virginia. Commenting on this situation in the mid80's, Markusen and McCurdy (1989) pointed to the absence of key military installations in the Chicago area and the disinterest in military markets shown by local commercial high tech firms. California's success in 'locking-in' the defense market to the development of a local high technology capacity may have simultaneously 'locked-out' all other potential high technology locations.

The present round of high technology development in the metropolitan 


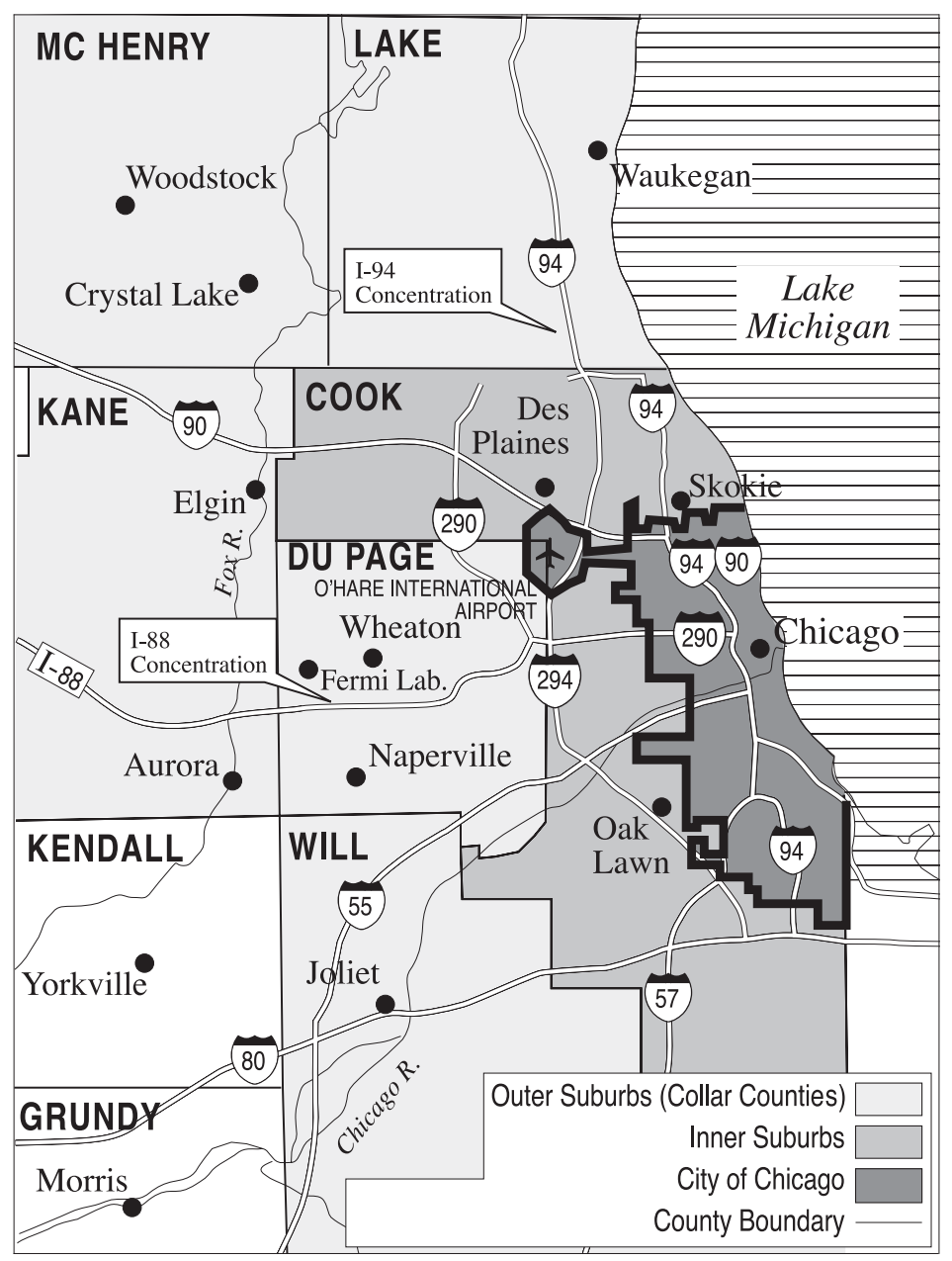

Map 1. High tech employment concentration in the Chicago Metropolitan Area

area has been noticeably devoid of any defense presence. Even the close proximity to Federal installations such as the Fermi National Accelerator Laboratory and the Argonne National Laboratory cannot be considered 'seedbed' factors that have contributed to the growth of the I- 88 cluster. Rather, the corridor development of high tech along major arteries is part of a process whereby the landscape of the Chicago metropolitan area has become increasingly polycentric, dotted by numerous employment subcenters (McMillen and McDonald 1997, 1998). The I-88 concentration is a result of mutually complementary public and market forces. Federal infrastructure investments in the area at the end of the 1960's (the E-W toll-way, the Lake Michigan water project and the Fermi National Accelerator Laboratory) combined with market forces such as demand for residential development to produce an initial round of residential development alongside I-88. The corporate presence in this area today includes Lucent Technologies, Amoco Research, Nalco 
Chemicals, Unisys, Computer Associates, HP Research and Platinum Technology. The present corridor development comprises of office, $\mathrm{R} \& \mathrm{D}$, corporate head offices and commercial land use.

A similar picture of self-reinforcing growth has developed in the southern portion of Lake County astride Route I-94 and the Edens Expressway which today includes some large corporate entities such as Abbot Labs, Baxter, Motorola and Hewitt Associates. While the extent of the phenomenon is more limited than along I-88, the basic pattern of demand for non-residential space reinforcing the demand for residential space in a circular fashion, is similar to that described for DuPage County. The demand generated by re-locating firms from the city of Chicago in search of lower taxes has combined with the suburban residential preferences of the skilled labor they employ. In addition, Lake County is a popular bedroom area for high wage commuters who work in the central city and the inner suburbs. The county as a whole acts as a net 'exporter' of workers with nearly 30,00 more employees leaving the county than entering on a daily basis. This implies that residential sprawl is likely to lead non-residential extension in the outward expansion of the metropolitan area. Despite the fact that residential land use occupies roughly the same area in both Lake and DuPage counties (over 140 sq. mls.), it accounts for only $31 \%$ of all total land coverage in the former versus $43 \%$ in the latter. Similarly, industrial and commercial land occupy a smaller share of total land in Lake county (7\%) than in DuPage County (11\%) (NIPC 1998).

\section{Method and data}

The approach adopted here involves translating high technology employment agglomeration (a place-of-work pattern) into urban sprawl (inherently, a place-of-residence phenomenon). We use a relatively transparent form of micro-simulation, the mechanics of which can be found in the Appendix. Our objective is to arrive at estimates of land consumption and the method used allocates estimated employment and population change associated with the high tech agglomerations, to different parts of the metropolitan area. In this respect, it has something in common with Garin-Lowry type allocation models. However, the ultimate aim is to arrive at estimates of land consumption in the outer suburbs that can then be used as input in other analytic frameworks (such as cost-benefit analysis). By disaggregating land consumption by income class, our method represents an extension to existing contributions to the 'costs of sprawl' debate. It addresses the neglected issue of quantifying the distribution of costs arising from sprawl. Employment deconcentration can often disproportionately disadvantage lower income groups through both 'spatial mismatch' and decreasing the amount of suburban open space available to them for recreation and leisure. Our method draws on work undertaken by Persky and Wiewel (2001) for calculating the costs and benefits of opening a plant at a 'greenfield' location in comparison with an inner city location. The simulation presented here departs however from previous work in that we analyze the industry-wide effects on urban sprawl rather than the effects arising through the movement of an individual plant.

The method involves three simple steps. The first relates to estimating all employment (direct and indirect) associated with the high technology agglomerations. Indirect employment is estimated using the REMI model for the 
Chicago metropolitan area ${ }^{1}$. While we only utilize the input-output functions of the REMI model and not its general equilibrium capabilities, its utility for the present analysis lies in the fact that it produces employment estimates disaggregated both across nine industries and across three different areas of metropolitan Chicago. These relate to the city of Chicago, the Inner Suburbs (that part of Cook County not covered by the city of Chicago) and the Outer Suburbs (DuPage, Lake, McHenry, Kane and Will counties). The REMI model allows us to assess how an employment change in any one of these three geographic areas impacts on any of the others. This impact is also provided at the 2-digit industry level. This is of particular importance as the industry detail acts as the link for translating the employment estimations into patterns of population change at a later stage.

Employment impacts are calculated for the actual (current) case where high tech is concentrated in the outer suburbs. However, in order to get an accurate picture of the impacts of the present agglomeration on urban sprawl, we need to posit a plausible counter-factual, or alternative-state-of-the-world, position. In this case, we posit two alternative scenarios. First we establish a spatial counterfactual asking what would have been the impacts on sprawl in the outer suburbs, had the present high tech agglomerations developed either in the city of Chicago or in the inner suburbs? The difference between these two situations gives us the real impact of the present situation. Second, we establish an industry counterfactual, asking how different would land consumption in the outer suburbs have been, in the event that a business service agglomeration of equal magnitude had developed in the suburbs?

The choice of the business services industry as a comparison group was based on the fact that this sector provides a plausible alternative to high tech for many suburban communities looking to expand their employment and tax base. Business services comprise activities such as advertising, credit reporting, commercial art and photography services, employment agencies, computer and software services etc. These activities often form the core of the backoffice employment that concentrates in many edge city employment centers. The sector also pays rather lower wages and employs more female and second wage-earner employment. This implies that first, the industry is likely to have a more limited economic impact than high technology manufacturing with lower income and employment multipliers. Second, workers in this industry are more likely to be looking for employment close to home, implying shorter commute times and a lower willingness to move residence in response to change of workplace.

The second step involves translating REMI-generated employment patterns into patterns of population change. In order to arrive at an estimation

\footnotetext{
${ }^{1}$ For a full description of the REMI model see Treyz et al. 1992 and Treyz 1993. The REMI model is an off-the-shelf regional econometric (CGE-type) model with developed forecasting and policy simulation capabilities. Here, however it is used in a limited, input-output capacity. We dictate a specific demand-side employment change (for example, a increase in workers in a given industry) and the model proceeds to compare the baseline (control) situation with the alternative situation, distributing all employment (direct and indirect) across nine 2-digit SIC industries. This simulation is run for each of the three area metropolitan sub-areas (outer suburbs, inner suburbs and city) with the same high tech employment 'disturbance' as the exogenous change each time. The model for the outer suburban area is run a further time to simulate the impacts of a business service disturbance. The advantage of the REMI model for this type of analysis lies in the fact that it disaggregates multiplier effects by sub-regions and allows for interactions between them.
} 
of land consumed in the outer suburbs we first need to know something of the characteristics of the population that is likely to live there as a result of the high tech concentrations and by extension, their housing choices. To this end, we make extensive use of actual data from the 1990 census using the $5 \%$ PUMS (Public Microdata Sample) for the areas in question (city of Chicago, inner and outer suburbs). We assume that the employees that work in the outer suburban high tech concentrations, and the induced jobs that these clusters generate, do not behave any differently in terms of their residential choice and household incomes from the actual employees recorded in the census sample. Using the proportions from the census data we assign each worker a place of residence and income group. The 'bridge' facilitating this translation is industry group. This is available both for the REMI-generated employment data and the census data.

The third step involves estimating land consumption in the outer suburbs as a result of the above population change. Land consumption is for nonresidential, residential and associated public land uses (roads, parks etc) categories. For non-residential consumption, we use a set of industry constants for the space requirements per worker in each of the nine primary industries. These constants were generated informally. A few large manufacturing and retail projects in the outer suburbs were reviewed and suburban planners were consulted. This resulted in a series of industry proportions similar to those used by the regional planning commission (NIPC 1998) ${ }^{2}$.

Residential land consumption is based on actual proportions for the outer suburbs of the Chicago metropolitan area based on the 1990 PUMS data. The estimates of new outer suburban households are distributed across three housing classes (multifamily, single detached $<1$ acre and single detached $>1$ acre) according to observed proportions from the census. The land consumption constants used here are 0.05 acres, 0.25 acres and 1.5 acres respectively. The figure for multifamily dwellings is based on consultations with suburban planners. The space requirements for single detached family homes $(<1$ acre and $>1$ acre) were derived directly from census data for the Chicago outer suburbs. The space requirements of these households are translated in acreages using the formula outlined in the Appendix. Finally, associated land uses are estimated as a fixed proportion of the residential and non-residential land.

To define 'high technology' industries we used the recent work of Acs and Ndikumwami (1998) that delimits a working set of 30, three-digit, industries. These 30 industries include all the 'core' activities of the biomedical industries, information technology, aeronautics, high technology instruments, research services and the energy and chemicals sectors. For the I-88 agglomeration, we obtained establishment-level employment data from the DuPage Planning Department relating to all high tech firms located within a 2 mile band north and south of Route I-88 stretching west to Aurora. Using this data set allowed us to identify the size of the high tech employment concentration as 34,645 employees in close to 500 establishments. This represents $71 \%$ of the DuPage County total. For I-94, we identified the high technology employment concentration as all establishments in the pre-defined SIC codes in a string of communities such as Buffalo Grove, Deerfield, Highland Park, Lincolnshire,

\footnotetext{
2 The proportions used are as follows: land consumption per worker in manufacturing is estimated as 0.05 acres; wholesale and retail sectors $=0.2$ acres; FIRE, services and government $=$ 0.02 acres; TCPU $=0.1$ acres, construction $=0$ acres and other $=0.02$ acres.
} 
Highwood etc. This high tech employment concentration accounted for 10,275 employees in about 120 firms (64\% of the Lake County total).

\section{Empirical findings}

\subsection{Outer suburban employment}

This geographic and sectoral distribution of outer suburban employment is presented in Table 1. Total direct high tech employment in the two clusters amounts to nearly 45,000 workers. When indirect employment is added, this figure expands to over 75,00 employees with an employment multiplier of 1.67. In addition, the forty-five thousand direct high tech employees generate a further 26,726 places of employment elsewhere in the metropolitan area, The vast majority of the employment effect in the outer suburbs is felt in manufacturing and services and $78 \%$ of all outer suburban employment is in these two sectors.

The simulated impact of the identical number of direct employees on the business services industry in the outer suburbs, yields smaller impacts with an employment multiplier of 1.49 . Nearly all the employment impact $(82 \%)$ is concentrated in the services sector with very little in the way of inter-industry linkages. These REMI estimates form the basis on which the population change is estimated.

\subsection{Allocating workers to place of residence}

Given the place of work patterns outlined in Table 1, we now allocate all workers to a place of residence based on actual census proportions. Across the whole metropolitan area, over 102,000 workers are linked to the high tech sector and the place of residence of these workers is presented in Table 2. Roughly two thirds of these are expected to live in the outer suburbs with a

Table 1. Direct and indirect employment in outer suburbs

\begin{tabular}{lcc}
\hline & \multicolumn{2}{l}{ Outer suburban employment } \\
\cline { 2 - 3 } & High tech & Business services \\
\hline Direct employment & 44,920 & 44,920 \\
\hline Total employment & & \\
Construction & 3,171 & 2,536 \\
Manufacturing & 23,596 & 535 \\
TCPU & 1,461 & 706 \\
Wholesale & 2,798 & 1,107 \\
Retail & 7,005 & 5,550 \\
FIRE & 1,513 & 1,334 \\
Service & 35,103 & 54,561 \\
Government & 445 & 438 \\
Other & 234 & 224 \\
Total & 75,326 & 66,991 \\
\hline Employment created elsewhere in metrop. area & 26,726 & 15,266 \\
\hline
\end{tabular}


Table 2. Place of residence and income group

\begin{tabular}{lcl}
\hline Place of Residence & High tech & Business services \\
\hline Outer suburbs & 16,116 & 14,134 \\
High income & 39,787 & 31,861 \\
Medium income & 10,975 & 10,459 \\
Low income & 67,878 & 56,454 \\
\hline Total & & \\
\hline Inner suburbs & 5,381 & 4,212 \\
$\quad$ High income & 12,726 & 9,586 \\
Medium income & 3,386 & 2,690 \\
Low income & 21,493 & 16,488 \\
\hline Total & & \\
\hline Chicago & 1,829 & 1,447 \\
High income & 6,619 & 4,715 \\
Medium income & 4,208 & 3,156 \\
\hline Low income & 12,656 & 9,318 \\
\hline Total & & \\
\hline
\end{tabular}

further $21 \%$ in the inner suburbs and $13 \%$ in the city of Chicago ${ }^{3}$. Of equal importance however is the income class of these residents. We expect this to be a cardinal feature in their housing choice and consequent land consumption patterns. Looking at the high tech workers who live in the outer suburbs we can see roughly $24 \%$ are high income, $60 \%$ are medium income and $16 \%$ are low income. It is the housing choices of these high tech residents that are the cause of pressures on land at the urban fringe.

By way of comparison, Table 2 also presents the place of residence for the business service simulation. Here the overall number of workers generated across the whole metropolitan area is considerably lower (over 82,000 thousand). Of them, some $60 \%$ are likely to choose an outer suburban place of residence. Within this group, $20 \%$ are low income. This is a larger proportion than registered in the case of high tech workers. It is in line with our expectation of lower paid, less mobile business service workers seeking employment closer to home.

Whichever case we observe, there would seem to a core body of some 50-60,000 employees with inelastic demand for outer suburban residence. The majority of these are high and middle income workers for whom marginal income increases and marginal costs of travelling may equalize at a distance that allows for outer suburban residence, irrespective of the relative location of place of work in the metropolitan area. Others are low income workers who are immobile and constrained to work close to place of residence. This profile of these outer suburban residents is now further examined.

\footnotetext{
${ }^{3}$ Note that the workers living in the inner suburbs or the city of Chicago may be either reverse commuters to the high tech corridors or employees of 'indirect' firms located closer to their residences. Our estimates suggest that the latter greatly outnumber the former.
} 


\subsection{Where do the residents of the outer suburbs work?}

We now attempt to disaggregate the profile of those residents of the outer suburbs whose employment is directly or indirectly related to the outer suburban high tech concentrations. The point of this exercise is to identify their place of work and derive some insights on their likely commuting patterns ${ }^{4}$. The focus in this section is on expanding the top (outer suburbs) section of Table 2.

As can be seen from Table 3, the vast majority (94\%) of outer suburban residents with jobs directly or indirectly linked to high tech, also work in the outer suburbs. Nearly 85 percent of this group are high and medium income and it is their housing choices that exert the greatest pressure on metropolitan expansion. The commuters can be identified from looking at those outer suburban residents who work either in the inner suburbs or in the city itself. They total roughly 6 percent of the outer suburban residents whose employment is linked to high tech. The vast majority of this group (some $85 \%$ ), are high and

Table 3. Place of work and income group for outer-suburban residents

\begin{tabular}{lrc}
\hline Place of work & High tech & Business services \\
\hline Outer suburbs & & \\
$\quad$ High income & 14,945 & 13,429 \\
Medium income & 37,543 & 30,529 \\
Low income & 11,476 & 10,209 \\
\hline Total & 63,964 & 54,167 \\
\hline Inner suburbs & & \\
High income & 565 & 448 \\
Medium income & 1,212 & 979 \\
Low income & 230 & 186 \\
\hline Total & 2,007 & 1,613 \\
\hline Chicago & & \\
$\quad$ High income & 353 & 255 \\
Medium income & 1,471 & 659 \\
Low income & 83 & 674 \\
\hline Total & 1,907 & 56,454 \\
\hline Overall total & 67,878 & \\
\hline
\end{tabular}

\footnotetext{
${ }^{4}$ While the estimation of commuting patterns from the REMI model's population figures is theoretically possible, this was not attempted here. The REMI approach to commuting is rather cumbersome. The model uses commuting data from the Census in order to making the resident income adjustments. Then migration estimates are calculated on the basis of employment to population figures and per capita real income figures (the latter including commuters by place of residence). REMI however, never explicitly reconciles these data. It never actually estimates interjurisdictional commuters. Nor does it break down the resident income adjustment by income group.
} 
middle income earners who are likely to generate commuting-related costs such as congestion, pollution, productivity loss and road accidents.

The business service simulation shows an even tighter overlap between place of work and place of residence. Some $96 \%$ of outer suburban residents in this sector are expected to work in the outer suburbs as well. Within this group a higher proportion are low income than in the high tech case $(19 \%$ for business services versus $15 \%$ for high tech). This serves to reinforce the earlier findings of a lower wage, less mobile labor force in this sector, less likely to work at a distance from place of residence.

\subsection{Non-residential and residential land consumption in the outer suburbs}

Non-residential land consumption refers to the open space directly absorbed by the construction of greenfield facilities in the outer suburbs and by the indirect consumption of land in commercial and other related activities induced by this direct activity. The REMI-generated employment estimates (direct and indirect) are used to proxy for the amount of land absorbed. Using fixed parameter values for land consumption by workers in each sector (see Note 2), we arrive at estimates of land absorption. These results are presented in Table 4 . High tech activity and associated economic activity in the outer suburbs, is expected to lead to the absorption of over 4,500 acres of open space. The retail sector is the largest single consumer of urban fringe land accounting for some $38 \%$ of the total of non-residential land consumption. This probably reflects the consumption demand of the high wage workers who characterize the high tech sector.

The main driver however of suburban sprawl is residential land use. This accounts for over $70 \%$ of all suburban land consumption in the high tech

Table 4. Residential and non-residential land consumption in the outer suburbs (acres)

\begin{tabular}{lrr}
\hline Land consumption & High tech & Business services \\
\hline Non residential & 0 & 0 \\
Construction & 1,220 & 29 \\
Manufacturing & 166 & 66 \\
TCPU & 632 & 185 \\
Wholesale & 1,749 & 1,013 \\
Retail & 39 & 23 \\
FIRE & 741 & 898 \\
Services & 12 & 7 \\
Government & 8 & 3 \\
Other & 4,567 & 2,224 \\
\hline Total & & \\
\hline Residential & 3,492 & 1,311 \\
High income & 6,084 & 1,863 \\
Medium income & 1,340 & 352 \\
Low income & 10,916 & 3,526 \\
\hline Total & 15,483 & 5,750 \\
\hline Overall total & &
\end{tabular}


case. The housing preferences of the high and medium income classes account for $90 \%$ of this demand and result in a loss of over 9,500 acres in residential development at the urban fringe (double the acreage consumed by nonresidential demand).

In comparison, the business service sector exerts much more modest demand on the urban fringe. Overall, the total acreage consumed under this scenario is only $37 \%$ of that absorbed via high tech development. More significant however are the relative proportions between non-residential and residential demand. In the business services case, non residential land consumption represents nearly $40 \%$ of the total estimate (in the high tech case this proportion is only $29 \%$ ). It also represents nearly $50 \%$ of the corresponding figure for high tech. In contrast, residential land consumption in the business services case is only $32 \%$ of the corresponding figure for high tech. Thus, while more modest in magnitude, business services sprawl seems to be driven by nonresidential demand. Nearly $45 \%$ of this derives from the retail sector alone.

\section{Comparing the alternatives}

We now compare the actual case with the counter-factual cases. The spatial counterfactual posits the development of the high tech agglomeration in two alternative locations; in the inner suburbs and in the city of Chicago ${ }^{5}$. The industry counterfactual attempts to establish what would have happened had an alternative agglomeration in the business services industry developed in the outer suburbs. Table 5 presents the results of these comparisons plus a sum-

Table 5. Comparison of sprawl effects: High technology versus business services

\begin{tabular}{|c|c|c|c|c|}
\hline \multirow[t]{3}{*}{ Effects on outer suburbs } & \multicolumn{3}{|l|}{ High tech } & \multirow{3}{*}{$\begin{array}{l}\begin{array}{l}\text { Business } \\
\text { services }\end{array} \\
\text { Outer suburbs }\end{array}$} \\
\hline & \multirow{2}{*}{$\frac{\text { Actual case }}{\text { Outer suburbs }}$} & \multicolumn{2}{|c|}{ Alternative scenarios } & \\
\hline & & I. Inner suburbs & II. Chicago & \\
\hline Total employees & 75,326 & 12,574 & 11,400 & 66,991 \\
\hline Total residents & 67,878 & 26,148 & 18,878 & 54,454 \\
\hline Total households & 35,539 & 13,690 & 9,854 & 29,572 \\
\hline $\begin{array}{l}\text { Non-residential land } \\
\text { consumption (acres) }\end{array}$ & 4,567 & 1,059 & 959 & 2,224 \\
\hline $\begin{array}{l}\text { Residential land } \\
\text { consumption (acres) }\end{array}$ & 10,916 & 4,346 & 3,168 & 3,526 \\
\hline $\begin{array}{l}\text { Associated public land } \\
\text { uses (acres) }\end{array}$ & 7,741 & 2,710 & 2,060 & 2,875 \\
\hline $\begin{array}{l}\text { Total land consumption } \\
\text { in outer suburbs (acres) }\end{array}$ & 23,224 & 8,115 & 6,187 & 8,625 \\
\hline
\end{tabular}

\footnotetext{
${ }^{5}$ It should be noted that the existence of supply constraints in housing and industrial property markets in the city of Chicago and perhaps the inner suburbs mean that this counterfactual can only be sustained over the short run. Over the medium to long term the relationship between place of work and residence as expressed in $P_{k w}(r y)$ is unlikely to remain constant.
} 
mary account of total land consumption estimates for the actual high tech case and three alternative states of the world. Total land consumption is simply the sum of the non-residential, residential and associated land use estimates. The latter, which relates to roads, sidewalks, public parking, public open spaces and the like, is estimated as a fixed proportion (one third) of all developed land (Downs 1992).

Total land consumption through current high tech development is estimated as over 23,000 acres. The two alternative spatial scenarios show much more modest impacts with suburban sprawl consuming over 8,000 acres if high tech had developed in the inner suburbs and over 6,000 acres if it had developed in the city. The business services scenario results in an estimate similar to that for the inner suburbs scenario. To put these magnitudes in perspective, we can note that O'Hare international airport occupies an area of close to 8,000 acres. Thus the difference between the actual situation and the hypothetical alternatives is a savings in outer suburban land equal to roughly two times the area of O'Hare airport.

One of the main engines driving high tech induced sprawl would seem to be the relatively inflexible housing behavior of the middle and high income groups when faced with different workplace scenarios. Our spatial scenario estimates indicate that suburban living is very attractive to these income classes irrespective of place of work. If these high technology clusters were to relocate to the city of Chicago, nearly 10,000 households would still choose to live in the outer suburbs, consuming over 6,000 acres of open space. Under the inner suburbs scenario over 13,500 households would still be living in the outer suburbs and would be transforming over 8,000 acres of open land into suburban use. In contrast, under the scenario of business services induced sprawl, workers housing preferences are of much more modest dimensions. While nearly 30,00 households are estimated to live in the outer suburbs their total land consumption (work and residence) only sums to 8,600 acres.

The ratio of land consumption per household reflects the space requirements of the different income groups. In the current case of outer suburban high tech, open space consumption per household in the outer suburbs is 0.67 acres. This reflects the absolute size of the high and middle income earners amongst the labor force employed (directly and indirectly) in high technology production in the outer suburbs. Under city of Chicago scenario, this ratio drops to 0.63 acres per household in the outer suburbs. While the absolute number of the outer suburban households falls considerably in this case, the persistence of the high and middle bracket earners in choosing outer suburban residences still accounts for this relatively high ratio. The inner suburbs scenario results in a more efficient ratio of 0.59 . This is because of the relative size of the low and middle income groups expected to be residing in the outer suburbs. Employment in the inner suburbs allows the lower income groups the opportunity of outer suburban residence to a greater extent than in the case of employment in the city. Their relatively larger presence in the outer suburbs combined with their less demanding space requirements, serves to moderate the size of the acreage per household ratio. Finally, the business services scenario records a considerably lower acreage per household (0.29) than any of the high tech scenarios. This reflects the particular characteristics of the industry (land intensive) and the low wage, predominantly female and immobile labor that it employs. The result is a large number of total households estimated in the outer suburbs but with very modest demands on land. 


\section{Conclusions}

At the most basic level, the above analysis has attempted to quantify the magnitude of land conversion in the outer suburbs arising from the present pattern of development of high technology employment concentrations. It has shown, unsurprisingly, that considerably less pressure on urban expansion could be expected in the hypothetical instances of the present high technology agglomerations developing elsewhere or developing with a different sectoral composition. In terms of pure acreage, this theoretical savings amounts to over two times the area of the O'Hare airport complex. However, this is a static outcome for what is inherently a dynamic issue. The problem of allocating workers to places of residence and employment is essentially a dynamic question that requires analyzing the simultaneous working of several markets (labor, housing, industrial land). Despite this limitation, the approach adopted here is nonetheless worthwhile providing initial estimates on which a more complex analysis can build.

Of equal significance to the raw estimates is the finding that the residential behavior of high income employees in high technology industries means pressure on the outer suburban land, whatever the scenario. As noted earlier, there exists a core body of (probably high income) employees whose demand for outer suburban residence is insensitive to place of work. Even in the spatial counterfactual cases, the estimated impact on urban sprawl arising from the housing choices and ancillary land requirements of these employees, results in land consumption roughly equivalent in magnitude to the land area occupied by O'Hare airport.

High skilled labor in high technology industries therefore exerts pressure on land at the metropolitan fringe, irrespective of place of work. Labor force mobility would seem to be a key issue when addressing the impact of high technology agglomerations on urban sprawl. As the location of this activity is driven by the supply of high skilled labor and as this labor would seem to generate demand for suburban living unconditional on place of work, the impact on metropolitan extension seems inevitable. The business services scenario illustrates that where the labor force has lower income and is less mobile, outer suburban land consumption is considerably lower. In the high tech sector however, our findings seem to indicate that if public policies could encourage greater development in the inner suburbs central city, this would primarily impact the residential choices of lower income workers.

This illustrates the mobility constraints on lower income labor when high technology employment centers are located at outer suburban locations. It also raises the issue of spatial mis-match as a major cost in urban sprawl. When a high technology firm relocates from an inner city or inner suburban location to the outer suburbs, a social cost is generated due to the mismatch that is created between place of residence and place of work. Less mobile and lower income workers with limited alternative employment horizons, are especially affected. Labor demand moves to the outer suburbs while they remain, in situ, in the city or inner suburbs. This social cost is often overlooked in the 'costs of sprawl' debate with more focus being given to the externalities of congestion, pollution and traffic accidents generated by commuters. However recent evidence suggests that these costs can be considerable (Guhathakurta and Wichert 1998; ITEP 2000; Persky and Wiewel 2001). 
This spatial mis-match and the policy prescriptions it has elicited (reverse commuting, affordable housing in the outer suburbs and the like), serves to stress some of the distributional consequences of urban sprawl. Of course, some of these costs are offset by the employment opportunities opened up for lower-income residents of the outer suburbs. The relative proportions of these costs and gains however is an empirical matter. Incorporating them, and adding an explicit welfare focus to the above analytical framework, remains a further challenge for future analysis.

\section{References}

Acs ZJ, Ndikumwami A (1998) High technology employment growth in major U.S. metropolitan areas. Small Business Economics 10:47-59

Anderson NB, Bogart WT (2001) The structure of sprawl: Identifying and characterizing employment centers in polycentric metropolitan areas. American Journal of Economics and Sociology $60(1): 147-169$

Audretsch DB (1998) Agglomeration and the location of innovative activity. Oxford Review of Economic Policy 14(2):18-29

Bania N, Eberts RW, Fogarty MS (1993) Universities and the startup of new companies: Can we generalize from Route 128 and Silicon Valley? Review of Economics and Statistics 75(4):761766

Beeson P, Montgomery E (1993) The effects of colleges and universities on local labor markets. Review of Economics and Statistics 75(4):753-761

Bogart WT (1998) The economics of cities and suburbs. Prentice Hall, NJ

Brueckner JK (2000) Urban sprawl; diagnosis and remedies. International Regional Science Review 23(2):160-171

Burchell EW (1997) Economic and fiscal costs (and benefits) of sprawl. The Urban Lawyer 29(2):159-181

Castells M, Hall P (1994) Technopoles of the World: The making of 21st century industrial complexes. Routledge, London

Cervero R (1986) Jobs-housing balancing and regional mobility. Journal of the American Planning Association 55(2):136-150

Cervero R (1986) Jobs-housing balance revisited; Trends and impacts in the San Francisco Bay Area. Journal of the American Planning Association 62(3):492-511

Cervero R (2001) Efficient urbanization: Economic performance and the shape of the metropolis. Urban Studies 38(10):1651-1671

DeVol RC (1999) America's high tech economy: Growth, development and risks for metropolitan areas. Milken Institute, Los Angeles, CA

Ding C, Bingham RD (2000) Beyond edge cities: Job decentralization and urban sprawl. Urban Affairs Review 35(6):837-855

Ding C, Knaap GJ, Hopkins LD (1999) Managing urban growth with urban growth boundaries: A theoretical analysis. Journal of Urban Economics 46:53-68

Downs A (1992) Stuck in traffic: Coping with peak-hour congestion. The Brookings Institution, Washington DC

Eisinger PK (1988) The rise of the entrepreneurial state: State and local economic development policy in the United States. University of Wisconsin Press, Madison, WI

Feldman MP (1994) The geography of innovation. Kluwer, Dordrecht

Garin RA (1966) A matrix formulation of the lowry model for intra-metropolitan actitvity location. Journal of the American Institute of Planners 32:361-364

Giuliano G, Small K (1991) Subcenters in the Los Angeles region. Regional Science and Urban Economics 21:163-182

Glaeser EL, Kallal H, Scheinkman J, Schleifer A (1992) Growth in cities. Journal of Political Economy 100:1126-1152

Glaeser EL, Kahn M (2001) Decentralized employment and the transformation of the American city. In: Gale WG, Rothenberg-Pack J (eds) Brookings-Wharton papers on urban affairs 2001. Brookings Institution, Washington, DC 
Glaeser EL, Kolko J, Saiz A (2001) Consumer city. Journal of Economic Geography 1:2750

Gottlieb PD (1994) Amenities as an economic development tool: Is there enough evidence? Economic Development Quarterly 8(3):270-285

Guhathakurta S, Wichert ME (1998) Who pays for growth in the city of Pheonix? An equity based perspective on suburbanization. Urban Affairs Review 33(6):813-838

Herzog HW, Schlottmann AW (1991) Metropolitan dimensions of high technology location in the U.S.: Worker mobility and residential choice. In: Herzog HW, Schlottmann AM (eds) Industry location and public policy. University of Tennessee Press, Knoxville TN, pp 169-189

ITEP (2000) Another way sprawl happens: Economic development subsidies in a Twin Cities suburb. Institute on Taxation and Economic Policy, Washington DC

Kotkin J, DeVol RC (2001) Knowledge-value cities in the digital age. Milken Institute, Los Angeles, CA

Krugman P (1991) Geography and trade. MIT Press, Cambridge, MA

Landis J (2001) Sprawl in California: Its extent, consequences and future. Public Policy Institute of California, San Francisco, CA

Lowry IS (1964) A model of the Metropolis. Memorandum RM-4035-RC, Rand Corporation, Santa Monica

Luger MI, Goldstein HA (1991) Technology in the garden: Research parks and regional economic development. University of North Carolina Press, Chapel Hill

Malecki EJ, Bradbury SL (1992) R\&D facilities and professional labor: Labor force dynamics in high technology. Regional Studies 26:123-136

Markusen A, Hall P, Glasmeier A (1986) High-tech America - The how, what, where and why of the sunrise industries. Allen and Unwin, Boston

Markusen A, McCurdy K (1989) Chicago's defense-based high technology: A case study of the 'seedbeds of innovation' hypothesis. Economic Development Quarterly 3(1):15-31

Markusen A, Chapple K, Schrock G, Yamamoto D, Yu P (2001) High tech and I-tech: How metros rank and specialize. Project on Regional and Industrial Economics, Humphrey Institute of Public Affairs, University of Minneapolis, MN

McDonald JF (1987) The identification of urban employment subcenters. Journal of Urban Economics 21:242-258

McMillen DP, McDonald JF (1997) Population density in suburban Chicago; A bid rent approach. Urban Studies 35(7):1119-1130

McMillen DP, McDonald JF (1998) Suburban subcenters and employment density in metropoli$\tan$ Chicago. Journal of Urban Economics 43:157-180

NIPC (1998) 1990 Land use summary for northeastern Illinois. Northeastern Illinois Planning Commisssion 〈available at http://www.nipc.cog.il.us/lu-sum.htm〉

Persky J, Wiewel W (2001) When corporations leave town: The costs and benefits of metropolitan job sprawl. Wayne State University Press, Detroit, MI

Reese LA (1992) Explaining the extent of local economic development activity: Evidence from Canadian cities. Environment and Planning C 10:105-120

Schneider M, Kim D (1996) The effects of local conditions on economic growth, 1977-1990: The changing location of high technology activities. Urban Affairs Review 32(2):131-156

Shearmur R, Doloreux D (2000) Science parks: Actors or reactors? Canadian science parks in their urban context. Environment and Planning A 32:1065-1082

Sivitanidou R, Sivitanides P (1995) The intrametropolitan distribution of R\&D activities: Theory and empirical evidence. Journal of Regional Science 35(3):391-415

Steinnes D (1982) Do 'people follow jobs' or 'do jobs follow people'? A causality issue in urban economics. Urban Studies 19:187-192

Stough RR, Haynes KE, Campbell HS (1998) Small business entrepreneurship in the high technology services sector: An assessment for the edge cities of the US National Capital region. Small Business Economics 10:61-74

Suarez-Villa L, Walrod W (1997) Operational strategy, R\&D and intra-metropolitan clustering in a polycentric structure: The advanced electronics industries of the Los Angeles Basin. Urban Studies 34(9):1343-1380

Thurston L, Yezer A (1994) Causality in the suburbanization of population and employment. Journal of Urban Economics 35:105-118

Treyz GI, Rickman DS, Shao G (1992) The REMI economic-demographic forecasting and simulation model. International Regional Science Review 12:2221-2254 
Treyz GI (1993) Regional economic modeling: A systematic approach to economic forecasting and policy analysis. Kluwer, Boston

Varga A (1998) University research and regional innovation: A spatial econometric analysis of academic technology transfers. Kluwer, Boston

\section{Appendix}

The method for converting the spatial pattern of employment into a place of residence pattern, involves the following steps:

\section{Step 1: Estimate direct and indirect employment}

We use REMI estimates to derive the number of workers (direct and indirect) in each industry, for each of the three places of work (city of Chicago (C), Inner Suburbs (IS) and Outer Suburbs (OS). The number of workers (N) at place of work $w(w=1 \ldots 3)$ and industry $k(k=1 \ldots 9)$ is:

$$
\mathrm{N}_{k w}
$$

\section{Step 2: Estimate population change}

We use proportions drawn from the Census relating to place of residence of workers by industry and income group. We distribute all values of $\mathrm{N}_{k w}$ according to these proportions with industry affiliation $(k)$ acting as the bridge. In this way, we assign an identity to each worker based on the behaviour of actual workers and we assume the distribution of workers resulting from our employment estimates follows that of the Census. All jobs are distributed across 27 potential categories ( 3 places of work $(w) \times 3$ places of residence $(r) \times 3$ income groups $(y))$ and this is repeated for each of the three locations and for the business services case. The proportion of workers in industry $k$ at place of work $w$, who live in place of residence $r(r=1 \ldots 3)$ and are in come group $y(y=1 \ldots 3)$ is given by $\mathrm{P}_{k w}(r y)$. The number of workers in industry $k$ and place of work $w$ is $\mathrm{N}_{k w}$. Multiplying this number by the above proportions gives $\mathrm{N}_{w}(r y)$. This is repeated for each of the three alternative locations and for the business services case.

$$
\mathrm{N}_{k w} * \mathrm{P}_{k w}(r y)=\mathrm{N}_{w}(r y)
$$

\section{Step 3: Estimate land consumption in the outer suburbs}

Non-residential land consumption (NRES) is based on place of work on the outer suburbs, i.e., $\Sigma w=$ OS. Note that from this point on, the analysis focuses only on those workers either working or residing in the outer suburbs (i.e., $\Sigma w=\mathrm{OS}$ and $\Sigma r=\mathrm{OS}$ ). NRES is represented by the number of workers in each industry in the outer suburbs for each of the scenarios multiplied by the proportion of land consumption in acres, $c$, for each industry $k\left(\mathrm{P}_{k c}\right)$, as outlined in Note 2.

$$
\mathrm{N}_{k w} * \mathrm{P}_{k c}=\mathrm{NRES}_{c}
$$


Residential land consumption is estimated in two stages. First, new household formation (NH) in the outer suburbs, needs to be estimated. For the purpose of land consumption in the outer suburbs, all household formation is assumed to be new: i.e., place of residence in the outer suburbs requires new land consumption via new building and more sprawl or pressures on the land market through housing turnover and filtering. A new household is assumed to form for roughly every 2 new residents in the outer suburbs.

$$
\mathrm{NH}=\mathrm{N}_{w}(r y) * .53
$$

Second, residential land consumption (RES) needs to be derived on the basis of new household formation. Again, taking only those households residing in the outer suburbs $(\Sigma r=\mathrm{OS})$ and multiplying them by census-derived proportions for residential land consumption will yield residential land consumption for each case. The residential categories used here are multifamily homes, single detached small homes $(<1$ acre $)$ and single detached large home $(>1$ acre). The acreages consumed by these housing choices are in the main censusderived and specified in the text. They are applied to each outer suburban household according to income level (3 categories). This is expressed as $\mathbf{P}_{h}(y)$, i.e. the proportion of average acreage consumption by income such that

$$
\mathrm{RES}=\mathrm{NH} * \mathrm{P}_{h}(y)
$$

Associated Public Land Use (APL) refers to roads, sidewalks, public parking, public open spaces etc. This is estimated as one third of all developed (nonresidential and residential) land.

$$
\mathrm{APL}=[\mathrm{NRES}+\mathrm{RES}] * .33
$$

